\title{
Cystic Fibrosis from Laboratory to Bedside: The Role of A20 in NF-KB-Mediated Inflammation
}

\author{
Aidan Bannon $^{\mathrm{a}}$ Shu-Dong Zhang ${ }^{\mathrm{b}}$ Bettina C. Schock ${ }^{\mathrm{a}}$ Madeleine Ennis $^{\mathrm{a}}$ \\ ${ }^{a}$ Centre for Infection and Immunity, and ${ }^{b}$ Centre for Cancer Research and Cell Biology, School of Medicine, Dentistry \\ and Biomedical Sciences, Queen's University Belfast, Belfast, UK
}

\section{Key Words}

Cystic fibrosis $\cdot$ Nuclear factor $\mathrm{kB} \cdot \mathrm{A} 20 \cdot$ Anti-inflammatory effects $\cdot$ Gene connectivity mapping $\cdot$ Drug repositioning

\begin{abstract}
Cystic fibrosis (CF) is a lifelong, inflammatory multi-organ disease and the most common lethal, genetic condition in Caucasian populations, with a median survival rate of 41.5 years. Pulmonary disease, characterized by infective exacerbations, bronchiectasis and increasing airway insufficiency is the most serious manifestation of this disease process, currently responsible for over $80 \%$ of CF deaths. Chronic dysregulation of the innate immune and host inflammatory response has been proposed as a mechanism central to this genetic condition, primarily driven by the nuclear factor $\mathrm{KB}$ (NF-KB) pathway. Chronic activation of this transcription factor complex leads to the production of pro-inflammatory cytokines and mediators such as IL-6, IL-8 and TNF-a. A20 has been described as a central and inducible negative regulator of NF-KB. This intracellular molecule negatively regulates NF$\mathrm{KB}$-driven pro-inflammatory signalling upon toll-like receptor activation at the level of TRAF6 activation. Silencing of A20 increases cellular levels of p 65 and induces a pro-inflam-
\end{abstract}

matory state. We have previously shown that $\mathrm{A} 20$ expression positively correlates with lung function $\left(\mathrm{FEV}_{1} \%\right)$ in CF. Despite improvement in survival rates in recent years, advancements in available therapies have been incremental. We demonstrate that the experimental use of naturally occurring plant diterpenes such as gibberellin on lipopolysaccharide-stimulated cell lines reduces IL-8 release in an A20-dependent manner. We discuss how the use of a novel bio-informatics gene expression connectivity-mapping technique to identify small molecule compounds that similarly mimic the action of A20 may lead to the development of new therapeutic approaches capable of reducing chronic airway inflammation in CF.

(c) 2015 S. Karger AG, Basel

\section{Introduction}

Cystic fibrosis (CF) is a chronic inflammatory multiorgan disease, caused by mutations in the CF transmembrane conductance regulator (CFTR) gene, which is expressed on many epithelial surfaces, and various cell types including myeloid and red blood cells $[1,2]$. It is the most common lethal genetic disease in Caucasian populations

\begin{tabular}{ll}
\hline KARGER 125:s & $\begin{array}{l}\text { () 2015 S. Karger AG, Basel } \\
1011-7571 / 15 / 0244-0301 \$ 39.50 / 0 \quad \text { Karger }\end{array}$ \\
$\begin{array}{l}\text { E-Mail karger@karger.com } \\
\text { www.karger.com/mpp }\end{array}$ & $\begin{array}{l}\text { This is an Open Access article licensed under the terms of the } \\
\text { Creative Commons Attribution-NonCommercial 3.0 Un- } \\
\text { ported license (CC BY-NC) (www.karger.com/OA-license), } \\
\text { applicable to the online version of the article only. Distribu- } \\
\text { tion permitted for non-commercial purposes only. }\end{array}$
\end{tabular}

Prof. Madeleine Ennis, Centre for Infection and Immunity

School of Medicine, Dentistry and Biomedical Sciences

Queen's University Belfast, Health Sciences Building

Lisburn Road, Belfast BT9 7AE (UK)

E-Mail m.ennis@qub.ac.uk 
( $~ 1$ in 3,000 live births). Inheritance is autosomal recessive in nature, and, within Caucasian populations, the carrier rate can be as high as 1:25 [3].

The incidence of CF in the United Arab Emirates and Saudi Arabia is $1: 16,000$ and 1:4,000, respectively [4, 5], while in Caucasian populations it is approximately 1:2,500, with comparable carrier rates throughout North America, the UK and Europe [6]. Eight thousand people are currently living with CF in the UK, with a median predicted survival of 41.5 years [7]. Current UK models predict that a child born today can typically expect to live to be 50 years of age or more [7], but advances in available therapies to date have been incremental.

More than 1,800 mutations have been identified in the CFTR gene, but the functional significance of only a small number is known [8-10]. The most common mutation, F508del, accounts for over two thirds of all mutations in northern Caucasian populations. This mutation is caused by a phenylalanine deletion at position 508 on chromosome 7. Despite the vast number of identified CFTR mutations, no other mutation accounts for more than $5 \%$ of CF cases in any one population [8-10].

The mutations in the CFTR gene most commonly affect the respiratory, gastrointestinal and reproductive systems. Up to $15 \%$ of CF babies are born with a meconium ileus, which is a sensitive differential sign of the disease at birth [11]. Whilst pancreatic insufficiency, biliary cirrhosis, CF-related diabetes mellitus and infertility are serious comanifestations of the disease [12], pulmonary insufficiency hallmarked by bronchiectasis, hypercarbia and chronic airway infection remains responsible for at least $80 \%$ of CF-related deaths [13].

In the lungs, ion imbalances caused by a loss of inhibition of the epithelial sodium channels as a result of CFTR dysfunction lead to the dehydration of epithelial surfaces, as excess sodium and water are reabsorbed into the cells. This dehydration of epithelial surfaces is in turn exacerbated by a loss of chloride, preventing the epithelium from rebalancing the low epithelial surface water volume. This mechanism manifests clinically as a build-up of purulent, thick mucus plugs which obstruct the airway [14$16]$. With continuing pulmonary obstruction and infection, structural lung damage such as bronchiectasis occurs, and there is a progressive loss of small airways function. This continuous vicious cycle begins in early childhood and continues through adolescence until death in adulthood [17].

Individuals with $\mathrm{CF}$ are born with histologically normal lungs, however it has been shown that inflammatory processes are present in the lungs of children as young as
4 weeks old, who are clinically free from infection [18]. Chronic dysregulation of the innate host inflammatory response has been proposed as central to the CFTR defect. Ex vivo experimental studies have shown an increased baseline level of pro-inflammatory mediators and cytokines in bronchoalveolar lavage samples of CF patients, further supporting this hypothesis $[3,19]$. Epithelial cell surface receptors recognize and respond to endogenous and exogenous pathogens via the activation of transcription factors such as the nuclear factor $\kappa \mathrm{B}(\mathrm{NF}-\kappa \mathrm{B})$ pathway, which is responsible for the production of pro-inflammatory mediators $[1,3]$.

Almost half of CF patients experience at least 1 pulmonary exacerbation every 6 months, and patients with over 2 exacerbations per year have an increased risk of a $5 \%$ decline in predicted $\mathrm{FEV}_{1} \%$ values [20]. The most common pathogens which affect CF patients are bacterial in nature: Pseudomonas aeruginosa, Staphylococcus aureus and methylpenicillin-resistant $S$. aureus (MRSA). Up to one third of children are chronically infected with $P$. aeruginosa by age 3 , whilst $80 \%$ of patients will be chronically infected with the pathogen by age 25 [21]. S. aureus colonizes up to $67 \%$ of patients aged 6-17, whilst MRSA is consistently distributed across age groups, with a prevalence of $25.7 \%$ [22]. Bacteria such as Stenotrophomonas maltophilia and Burkholderia cepacia are less common in patients with standard infection rates of 13.7 and 2.5\%, respectively; however, they are also associated with significant reductions in $\mathrm{FEV}_{1} \%$ values and, in some acute infectious exacerbations, with early mortality [3, 22]. Chronic $P$. aeruginosa infection in particular is associated with increased disease severity and a poorer prognostic outcome, and therefore the mechanism by which the innate immune system and host inflammatory response is dysregulated is an area of significant interest to clinicians and scientists alike [23-25].

This review is focused specifically on the mechanism of NF- $\mathrm{kB}$-driven lung inflammation in $\mathrm{CF}$ and on the identification and role of cytoplasmic protein A20 as a negative regulator of this cascade. It includes novel therapeutic approaches with the potential to reduce chronic airway inflammation in CF by focusing on this central mechanism.

\section{Innate Immunity in CF}

The ability to respond to pathogens is critical for health and survival. Pathogens are identified by pattern recognition molecules, namely the toll-like receptors (TLRs) on 
epithelial and immune cells [1]. In CF, activation of TLR2, TLR-3 or TLR-4 triggers an acute innate immune response that is largely mediated by the transcription factor $\mathrm{NF}-\mathrm{\kappa B}$ to target gene expression and mediate the expression of inflammatory cytokines [26]. Several studies [2729] have shown altered TLR-4 expression in CF airway epithelial cells, which contributes to an increased inflammatory and deranged immune response.

In a normal healthy host, TLR- 4 is a pattern recognition molecule that specifically binds to the outer core oligosaccharide of lipopolysaccharide (LPS), initiating an internalized response and signalling airway epithelial activation [30]. This immune response is rapid and self-limiting and involves neutrophil recruitment, regulation of apoptosis and maintenance of airway epithelial integrity. In patients with $\mathrm{CF}$, this instead leads to a prolonged activation of the inflammatory response, as the CFTR airway and lung epithelial cells are unable to endocytose LPS and initiate a regulated NF- $\kappa B$ response $[30,31]$.

In addition, increases in the cell membrane expression of compounds such as asialo-GM1 enable an increased attachment of both $P$. aeruginosa and $S$. aureus to the airway epithelium, without the initiation of the normal CFTR-mediated immune response [32, 33]. The mucopurulent environment of the CF airway acts as a reservoir for bacteria and infection, which leads to a prolonged and ineffective immune-mediated response, anecdotally referred to as the vicious cycle of CF. TLR- 4 activation leads to NF- $\kappa \mathrm{B}$ activation and to subsequent translation of NF$\kappa \mathrm{B}$-driven target genes such as IL-8.

\section{In vitro Methods to Study Airways Inflammation in $\mathbf{C F}$}

The epithelial cells lining the respiratory tract are the first point of contact between the outside world (bacteria, viruses, dust etc.) and the body. Initially, it was thought that these cells had a mere barrier function with the cilia pushing the foreign agents and mucus up to the mouth to be expectorated or swallowed. However, it is now recognized that these cells are key players in the innate immune response and can secrete a host of inflammatory mediators, chemotactic agents and antimicrobial substances. Several approaches have been adopted to study these cells in the laboratory. There are a number of immortalized epithelial cell lines with and without mutations in CFTR available [34]. In order to study primary epithelial cells, a number of investigators have isolated these cells from human lungs [35] and nasal polyps [36]. Although excellent sources for cells, both approaches suffer from some disadvantages. Human lungs from patients with CF are only obtained from those with end-stage disease who are undergoing transplantation. Thus, it is difficult to obtain cells from patients with milder mutations and impossible to do longitudinal studies. For nasal polyps, access to surgically resected material is required, and, again, longitudinal studies are not possible. We therefore developed a method to isolate and grow primary epithelial cells using nasal brushings from patients with CF [37]. These cells can be obtained from patients with different mutations and can be utilized for mediator release studies as well as for the investigation of the ion channel function [38]. The procedure is minimally invasive and is well tolerated by patients and healthy volunteers. It can therefore be used to study epithelial cells from patients with milder mutations as well as to follow longitudinal changes in epithelial cell function.

\section{Sustained NF-KB-Mediated Inflammation Is a Hallmark of CF}

$\mathrm{NF}-\kappa \mathrm{B}$ is a protein complex that controls the transcription of DNA. Found in almost all human cell types, its activation is central to the innate immune response. In ensuring a timely termination of inflammation, NF- $\kappa B$ is tightly regulated. In individuals with underlying airways disease such as CF, this regulation is compromised, leading to sustained NF- $\kappa \mathrm{B}$ activation and heightened chronic inflammation, with further decreasing lung function [39].

Under normal conditions, NF- $\kappa \mathrm{B}$ is inactive, bound by a complex of inhibitory proteins such as I $\kappa \mathrm{B} a$. Stimulation of the epithelial TLRs or TNF receptors by both exogenous and endogenous pathogens leads to the induction of a series of signalling cascades and the subsequent degradation of the I $\mathrm{B}$ complex, which leads to the release of NF- $\kappa B$ [40]. NF- $\kappa B$ consequently translocates to the nucleus and activates pro-inflammatory genes, such as p50 and p65, as depicted in figure 1, which maintain this state of inflammation through the release of inflammatory cytokines. Within this receptor-ligand complex, a series of signal transduction pathways are activated before the translocation of p50 and p65 to the nucleus; most notably these are the MyD88 and TRAF subunit 2 and 6 proteins, which are ubiquinated receptor molecules within this cascade [41, 42].

Increases in pro-inflammatory mediators such as IL-6, IL-8, TNF- $\alpha$ and arachidonic acid metabolites have been 
observed in CF patients $[39,43,44]$. Concurrently, concentrations of anti-inflammatory substances such as IL10 and lipoxin are reduced, favouring a state of unabated inflammation $[45,46]$.

Maintaining cellular homeostasis is important for cells. Autophagy is a lysosomal process that induces the degradation of cytoplasmic constituents such as proteins, lipids and organelles [47]. Thereby, autophagy is a pivotal regulator of physiological processes such as development, cell survival, differentiation and senescence, as reviewed earlier [48], as well as regulating inflammation and innate and adaptive immune responses [49], functions strongly regulated by NF- $\kappa \mathrm{B}$. On a molecular level, autophagy and NF- $\kappa \mathrm{B}$ share common upstream signals and regulators and can control each other through positive or negative feedback loops, thus ensuring homeostatic responses [48]. In CF, the process of autophagy is defective, leading to an accumulation of misfolded or defective proteins such as CFTR, which has been described to drive autophagy inhibition [50]. Furthermore, autophagy is involved in the formation of lysosomes and through a distinct phenomenon called LC3-associated phagocytosis facilitates the processing of TRL-4 phagosomes, for example [51]. Interestingly, it has been shown that CF epithelial cells preferentially utilize recycling rather than lysosomal degradation upon LPS stimulation, which may be due to the inhibited autophagy in CF cells [26]. Rescuing autophagy may therefore interrupt the vicious cycle linking defective CFTR and lung inflammation [50,51], and the stimulation of autophagy (e.g. by rapamycin) has been shown to suppress lung inflammation in a model of CF [52]. Considering the important role of NF- $\kappa \mathrm{B}$ in the process of autophagy, the inhibition of NF- $\kappa \mathrm{B}$ may be associated with reduced autophagy. Therefore, the goal of our research is not to inhibit NF- $\kappa \mathrm{B}$ expression and activation, but to normalize it to a level observed in nonCF cells.

\section{A20 Is a Central Negative Regulator of NF-KB}

A20 (TNFAIP-3) is a central and inducible regulator of NF- $\kappa \mathrm{B}$, regulating multiple signalling cascades. Basal expression in most cells is normally low; however, it is rapidly upregulated in response to previously described pathogenic stimuli, such as TNF- $\alpha$ and LPS [53]. A20 negatively regulates NF- $\kappa \mathrm{B}$ driven pro-inflammatory signalling upon TLR activation at the level of the TRAF6 activation $[42,43]$ (fig. 2). Persistent NF- $\kappa B$ activation

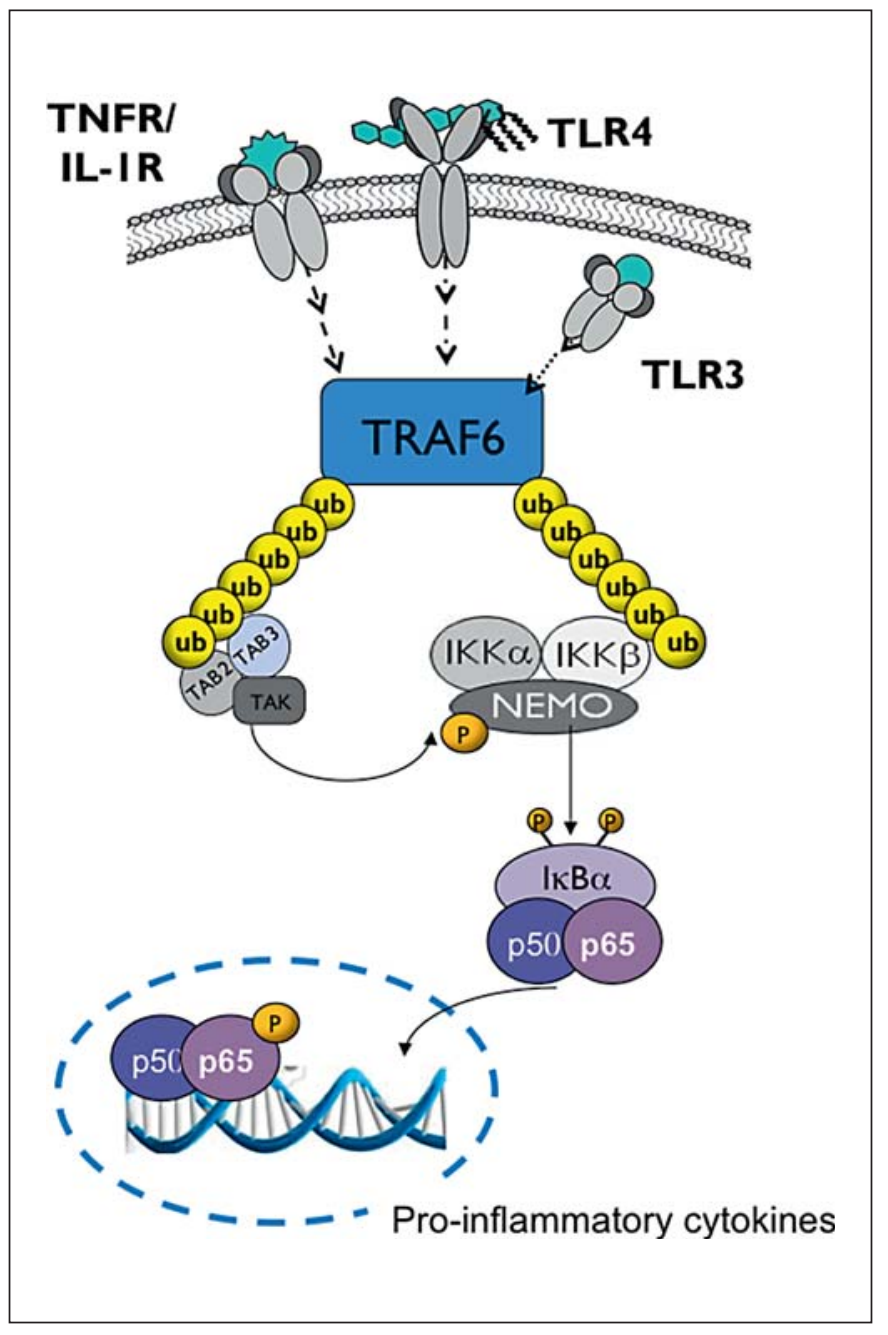

Fig. 1. Schematic outline showing the production of pro-inflammatory cytokines via TLR-4-mediated TRAF6 activation of NF$\kappa \mathrm{B}$ and the translocation of p50 and p65 to the nucleus. IKK $\alpha=$ Inhibitor of NF- $\kappa B$ kinase subunit $\alpha$; IKK $\beta=$ inhibitor of NF- $\kappa B$ kinase subunit $\beta$; IL-1R = interleukin-1 receptor; $N E M O=N F-\kappa B$ essential modulator; $\mathrm{p} 50=\mathrm{p} 50$ subunit of NF- $\kappa \mathrm{B}$; p65 = p65 subunit of NF- $\kappa B$; TAB2 = transforming growth factor- $\beta$-activated kinase 1 binding protein 2 ; TAB3 = transforming growth factor$\beta$-activated kinase 1 binding protein 3 ; TAK = transforming growth factor- $\beta$-activated kinase; TNFR = tumour necrosis factor receptor; TRAF6 $=$ TNF receptor-associated factor 6 ; $\mathrm{ub}=\mathrm{ubiq}$ uitin.

suggests that this tightly regulated signalling pathway is distorted in CF [26, 31, 54]. The PubMed database was searched for (A20 or TNFAIP-3) and CF, and abstracts from the European Cystic Fibrosis Society conferences were examined. The patent database was searched for gibberellin $\left(\mathrm{GA}_{3}\right)$ derivatives. 


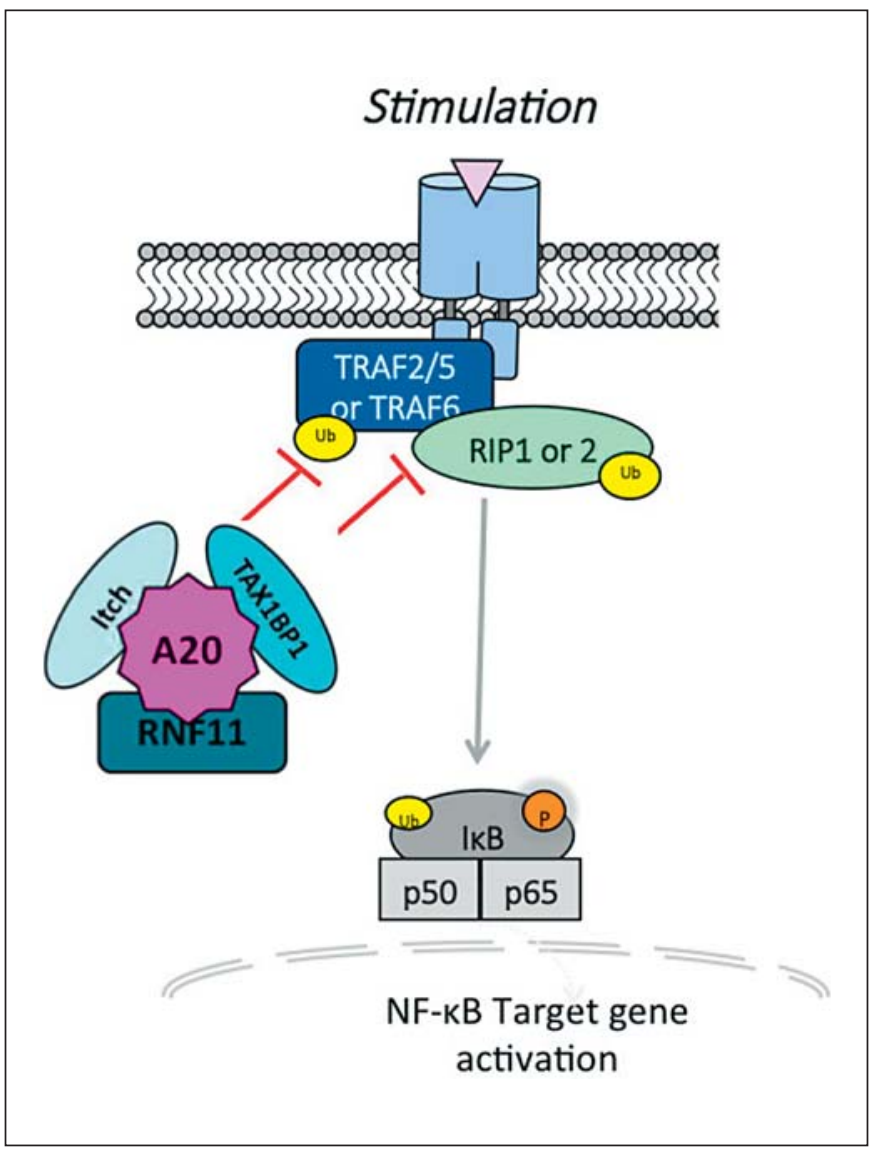

Fig. 2. The role of the A20 ubiquitinating complex at the TRAF6 level. Modified from Kelly et al. [40].

While the first innate response to pathogens is mediated by pro-inflammatory NF- $\kappa \mathrm{B}$, the induction of A20 is described as the 'anti-inflammatory arm' of NF- $\kappa B$ signalling [55]. The A20-TRAF6 axis is critical in preventing LPS-stimulated NF- $\kappa B$ activation: A20 silencing restores TRAF6 action and increases NF- $\kappa \mathrm{B}$ activation following stimulation with LPS [56]. Following TLR4 activation, A20 first inactivates TRAF6 by deubiquitination and disruption of the interaction with an ubiquitin ligase and then ubiquitinates TRAF6, which initiates proteasomal degradation $[41,42]$.

Inhibitory A20 action also depends on the A20 ubiquitin-editing complex formed with RNF11, Itch (ligase) and TAX1BP1 (TRAF6-binding protein) $[57,58]$. This interaction is rapid and transient and governs A20 action by promoting TRAF6 deubiquitination and disrupting TRAF6 association with the ligase, thereby terminating the NF- $\kappa$ B activation [41]. Similarly, in TNF receptor sig- nalling, A20 removes the activating K63-polyubiquitin of the protein kinase RIP (RIPK1), then acts as a ligase, promoting K48 polyubiquitination and degradation of RIPK1 [59].

However, a recent paper by De et al. [60] has suggested that in mice the deubiquitinase activity of A20 is not needed for normal NF- $\mathrm{KB}$ signalling, suggesting that this role is taken over by a different deubiquitinase.

\section{A20: A Multidisease Model}

A20, a zinc finger protein, was initially researched as a tumour suppressor gene [61], but has since been implicated in various inflammatory diseases such as inflammatory bowel disease, systemic lupus erythematosus, type 1 diabetes, psoriasis, rheumatoid arthritis and multiple sclerosis, where it serves as a susceptibility gene/biomarker of disease development [62]. In animal studies, mice lacking enterocyte A20 developed an overwhelming systemic inflammation following treatment with TNF- $\alpha$ [63]. A20 also inhibits NF- $\mathrm{BB}$ activation in bronchial epithelial cells following influenza infection [64], and enhanced A20 mRNA expression was observed in mice following the introduction of $P$. aeruginosa infection after a 1-hour incubation period [65].

\section{A20 in CF Airway Disease}

In the lung, A20 is rapidly induced by $P$. aeruginosa and is essential for the termination of the TLR4-signalled release of IL-8 from primary airway epithelial cells [66]. A20 prevents the translocation of p65 to the nucleus, thus mediating and downregulating the inflammatory response. In keeping with this, it has been found that the silencing of A20 increases cellular levels of p65 and induces a pro-inflammatory state [67]. Transient increases in A20 following the stimulation of primary nasal epithelial cells with LPS have been shown, but CF primary nasal epithelial cells express less A20 basally and following LPS stimulation, suggesting that A20 expression is related to CFTR functionality [39].

In $\mathrm{CF}$, the adapter protein TAX1BP1 within the ubiquitin-editing complex is shown to be significantly reduced in LPS-treated cells $[39,40]$. In this complex, A20 and TAX1BP1 directly interact to prevent TRAF6 polyubiquitination and thus stop the TLR-mediated inflammatory signalling response. In the absence of TAX1BP1, A20 cannot bind to target proteins $[41,57]$. 


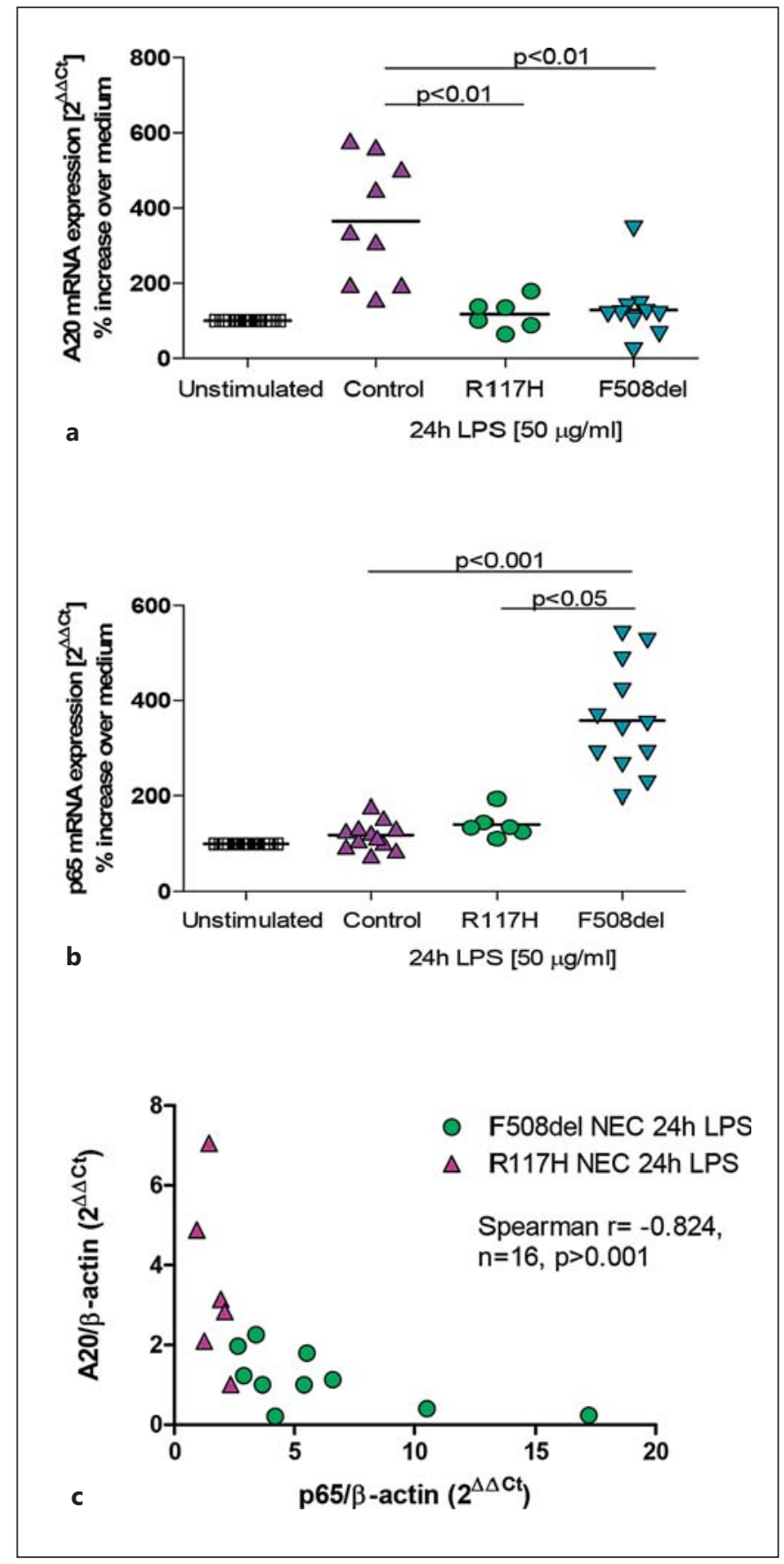

Fig. 3. Role of A20 in CF. a, b Kruskal-Wallis one-way ANOVA $(\mathrm{n}=6-10)$. A20 expression (a) and p65 expression (b) are related to the CF genotype. c A20 expression correlates negatively with NF- $\mathrm{B}$ (p65) expression. Modified from Kelly et al. [39, 68].
Kelly et al. [68] explored the relationship of TAX1BP1 and A20 and found that F508:F508del (homozygous) epithelial cells expressed significantly less A20 than R117H/F508del (heterozygous), $\mathrm{p}<0.05$ (fig. 3a). As expected, NF- $\kappa \mathrm{B}$ (p65) expression is increased in CF genotypes compared to non-CF epithelial cells (fig. 3b). Interestingly, Kelly et al. [68] also reported TAXB1BP1 expression to be only reduced in F508del (homozygous) CF cells but not in those with a milder disease (R117H/F508del).

\section{A20 Expression Correlates with Lung Function in CF}

A20 expression in both of the predominant CF genotypes F508:F508del and R177H/F508del is inversely proportional to p65 expression $[39,68]$, which has a direct correlation with NF- $\kappa B$ activity [69] (fig. 3c). To date, these are the only mutations which have been examined with respect to A20 expression. Most importantly, Kelly et al. [68] also observed a significant relationship between deteriorating $\mathrm{FEV}_{1} \%$ and basal A20 expression. Of particular note, those cases with the poorest lung function were also those with the most severe reduction in A20 expression.

$\mathrm{CF}$ is a heterogeneous disease, and the phenotypic severity of the condition can be significantly varied; these findings suggest that the reduction of A20 in epithelial cells largely reflects the genotype and disease severity. The above findings suggest that A20 has the potential to be a predictor of both inflammation and disease severity in $\mathrm{CF}$, which has merited further exploratory studies focusing on the role of A20 and other, similar molecules as mediators of inflammation within CF.

\section{Induction of $\mathrm{A} 20$ by $\mathrm{GA}_{3}$ Is Anti-Inflammatory}

$\mathrm{GA}_{3}$ hormones are naturally occurring plant diterpenes biosynthesized from ent-kaurenes implicated in plant growth [70]. Several diterpenoids possess strong anti-inflammatory properties. Most notably, forskolin can reduce inflammation in asthma and histamine release through cAMP-dependent mechanisms; however, forskolin is independent of the mechanisms discussed in this context [71]. $\mathrm{GA}_{3}$ has been shown to have anti-inflammatory properties in diabetic mice [72]. Patents exist to develop $\mathrm{GA}_{3}$ formulations for the treatment of diabetes and its complications [73], prostatitis and psoriasis [74], thereby highlighting the increasing interest in developing $\mathrm{GA}_{3}$ for preclinical and clinical trials. 
As a proof of principle, our preliminary data have confirmed that $\mathrm{GA}_{3}$ pretreatment significantly induced A20 in LPS-stimulated bronchial epithelial cells, which was associated with a significant reduction in LPS-induced IL-8 release (fig. 4). Therefore, we hypothesize that pharmacological induction of A20 could be a potential new treatment for persistent inflammation in CF [75].

\section{Modification of A20: Anti-Inflammatory Immune Response-Enhancing Therapy}

Given its role in modulating innate immunity and NF$\kappa \mathrm{B}$ activation, the pharmacological induction of A20 can be predicted to be anti-inflammatory. In mice, the viral transfer of A20 attenuates ovalbumin-induced allergic asthma, inhibits mucus production and cytokine release and prevents airway hyperresponsiveness [76]. Probiotics facilitate their anti-inflammatory action through the induction of A20, and it has been shown that A20 induction by modified $P$. aeruginosa attenuates allergic airway inflammation in mice and human bronchial epithelial cells [77].

Advances in CF treatment will see an aging CF population in the future. Despite recent advances in CFTR modulatory therapies, there is a need to introduce new firstin-class (different mechanism of action than already approved medicines) anti-inflammatory drugs that can normalize the inflammatory response and help to contribute to healthier aging in patients with CF.

The development of new first-in-class medicines costs approximately USD 1.2 billion for a single approved drug $[78,79]$ and can take up to $10-15$ years to develop [80, 81]. Many of these drugs perform well in the preclinical testing but fail when tested in humans. The failure to translate drug candidates from animal models to humans has led to questions about the utility of in vivo studies [82, 83]. Alternative approaches and more predictive models of drug research are identified areas of interest for drug research and development.

\section{Drug Repositioning, Connectivity Mapping and Making New Drugs from Old}

Drug repositioning offers an exciting opportunity to utilize and repurpose existing, licensed treatments, with the major benefit of providing a far more rapid route to clinic than by novel drug discovery approaches, removing the need for many animal experiments, particularly toxi-

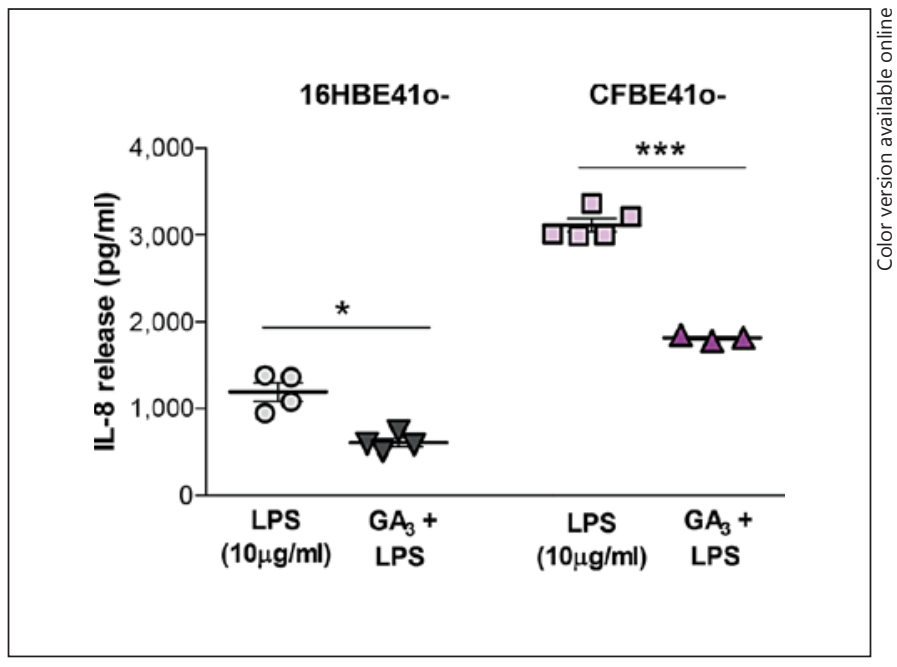

Fig. 4. Effect of $\mathrm{GA}_{3}$ pretreatment on LPS-induced IL-8 release from control (HBE) and CF (CFBE) epithelial cells. ${ }^{*} \mathrm{p}<0.0$, *** $\mathrm{p}<0.001$ (one-way ANOVA).

cology, efficacy and dose-tolerance studies. There are two main approaches to drug repositioning: firstly, to investigate drugs within the mechanism of action for which they are already licensed, for example the repositioning of sildenafil by Pfizer for use in erectile dysfunction [84]. The more innovative approach, known as gene expression connectivity mapping, aims to identify novel targets for existing drugs. Gene mapping is an advanced bio-informatics technique to establish the connections among different biological states via their gene expression profiles/signatures. One major application of connectivity mapping is to identify potential small molecule compounds able to inhibit a disease state or regulate the expression of a small number of genes $[85,86]$. This has been successfully applied to phenotypic targeting in a different setting: entinostat was predicted and subsequently validated as an effective inhibitor of the disease phenotype in acute myeloid leukaemia [87].

Together we performed a compound search using gene expression connectivity mapping to identify existing drugs that could induce A20 expression [88]. A total of 53 individual gene array sample sets of airway epithelial cells from patients with and without CF from 6 independent public datasets were used.

Within the process of gene expression connectivity mapping, genes associated in their mRNA expression to that of A20 were determined. The so-called A20-associated genes together with the seed gene A20 form the gene signature, a short list of important genes, selected from 
the gene array data through regression analysis. The genes identified in CF were activating transcription factor 3 , intercellular adhesion molecule-1, a member of the RAS oncogene family (RAB5C) and domain-containing protein (DENND4A). Quantitative RT-PCR analyses in $\mathrm{CF}$ and non-CF cell lines confirmed a reduced basal expression and a lower LPS-induced expression of these genes, similar to A20 in these genes $[39,88]$. Together with A20, these A20 associates then served as an input to the connectivity mapping process (www.broadinstitute. org) to predict small molecules already licensed for the use in humans that will enhance A20 expression. Currently, we are testing these molecules to check that they act as A20 inducers and have anti-inflammatory effects on our isolated epithelial cell preparations.

\section{Conclusion}

A20 is crucial in regulating the innate NF- $\kappa \mathrm{B}$-driven response to infections. As A20 expression in airway epithelial cells from patients with CF is reduced, it remains a potential therapeutic target to normalize inflammation; however, a drug to increase A20 expression is not currently available. Data using $\mathrm{GA}_{3}$ strongly suggest that the pharmaceutical induction of A20 reduces NF- $\kappa B$-driven inflammation in airway epithelial cells. Our current work has found genes which behave like A20, and, using connectivity mapping, we are predicting several drugs already licensed for use in humans that are potentially capable of inducing A20. This approach, if successful, will take our work on isolated cells truly from bench to bedside.

\section{References}

1 Rowe SM, Miller S, Sorscher EJ: Cystic fibrosis. N Engl J Med 2005;352:1992-2001.

2 Lange T, Jungmann P, Haberle J, et al: Reduced number of CFTR molecules in erythrocyte plasma membrane of cystic fibrosis patients. Mol Membr Biol 2006;23:317-323.

-3 O'Sullivan BP, Freedman SD: Cystic fibrosis. Lancet 2009;373:1891-1904.

4 Frossard PM, Lestringant G, Girodon E, et al: Determination of the prevalence of cystic fibrosis in the United Arab Emirates by genetic carrier screening. Clin Genet 1999;55:496497.

5 Mathew PM, Hamdan JA, Nazer H: Cystic fibrosis presenting with recurrent vomiting and metabolic alkalosis. Eur J Pediatr 1991; 150:264-266.

6 Ratjen F, Doring G: Cystic fibrosis. Lancet 2003;361:681-689.

7 Dodge JA, Lewis PA, Stanton M, et al: Cystic fibrosis mortality and survival in the UK: 1947-2003. Eur Respir J 2007;29:522-526.

8 Lao O, Andres AM, Mateu E, et al: Spatial patterns of cystic fibrosis mutation spectra in European populations. Eur J Hum Genet 2003; 11:385-394.

9 Walters S, Mehta A: Epidemiology of cystic fibrosis; in Hodson M, Geddes DM, Bush A (eds): Cystic Fibrosis, ed 3. Boca Raton, CRC Press, 2007, pp 21-45.

10 Jennings MT, Riekert KA, Boyle MP: Updates on key emerging challenges in cystic fibrosis. Med Princ Pract 2014;23:393-402.

$\checkmark 11$ Anderson DH: Cystic fibrosis of the pancreas and its relation to celiac disease. Am J Dis Child 1938;56:344.

12 Wilschanski M, Durie PR: Patterns of GI disease in adulthood associated with mutations in the CFTR gene. Gut 2007;56:1153-1163.
13 Cystic Fibrosis Foundation Patient Registry: 2006 Annual Data Report to the Center Directors. Bethedsa, Cystic Fibrosis Foundation, 2007.

14 Matsui H, Grubb BR, Tarran R, et al: Evidence for perciliary liquid layer depletion, not abnormal ion composition in the pathogenesis of cystic fibrosis airways disease. Cell 1998;95: 1005-1115.

15 Matsui H, Wagner VE, Hill DB, et al: A physical linkage between cystic fibrosis airway surface dehydration and Pseudomonas aeruginosa biofilms. Proc Natl Acad Sci USA 2006;103: 18131-18136.

16 Boucher RC: Airway surface dehydration in cystic fibrosis: pathogenesis and therapy. Annu Rev Med 2007;58:157-170.

17 Tomashefski JF, Abramowsky CR, Dahms BB: The pathology of cystic fibrosis; in Davis PB (ed): Cystic Fibrosis. New York, Dekker, 1993, pp 435-489.

18 Khan TZ, Wagener JS, Bost T, et al: Early pulmonary inflammation in infants with cystic fibrosis. Am J Respir Crit Care Med 1995;151: 1075-1082.

19 McGarvey LP, Dunbar K, Martin SL, et al: Cytokine concentrations and neutrophil elastase activity in bronchoalveolar lavage and induced sputum from patients with cystic fibrosis, mild asthma and healthy volunteers. J Cyst Fibros 2002;1:269-275.

20 De Boer K, Vandemheen KL, Tullis E, et al: Exacerbation frequency and clinical outcomes in adult patients with cystic fibrosis. Thorax 2011;66:680-685.

21 Chmiel JF, Berger M, Konstan MW: The role of inflammation in the pathophysiology of CF lung disease. Clin Rev Allergy Immunol 2002; 23:5-27.
22 Cystic Fibrosis Registry: Cystic Fibrosis Our Focus. Annual Data Report, 2013. Bromley, Cystic Fibrosis Trust, 2014.

23 Szaff M, Hoiby N, Flensborg EW: Frequent antibiotic therapy improves survival of cystic fibrosis patients with chronic Pseudomonas aeruginosa infection. Acta Paediatr Scand 1983;72:651-657.

24 Regelmann WE, Elliot GR, Warwick WJ, et al: Reduction of sputum Pseudomonas aerugino$s a$ density by antibiotics improves lung function in cystic fibrosis more than bronchodilators and chest physiotherapy alone. Am Rev Respir Dis 1990;141:914-921.

25 Sadikot RT, Zeng H, Joo M, et al: Targeted immunomodulation of the NF-kappaB pathway in airway epithelium impacts host defense against Pseudomonas aeruginosa. J Immunol 2006;176:4923-4930.

26 Kelly C, Canning P, Buchanan PJ, et al: Tolllike receptor 4 is not targeted to the lysosome in cystic fibrosis airway epithelial cells. Am J Physiol Lung Cell Mol Physiol 2013;304:371378.

27 Greene CM, Carroll TP, Smith SG, et al: TLRinduced inflammation in cystic fibrosis and non-cystic fibrosis airway epithelial cells. J Immunol 2005;174:1638-1646.

28 Hauber HP, Tulic MK, Tsicopoulos A, et al: Toll-like receptors 4 and 2 expression in the bronchial mucosa of patients with cystic fibrosis. Can Respir J 2005;12:13-18.

29 John G, Yildirim AO, Rubin BK, et al: TLR4-mediated innate immunity is reduced in cystic fibrosis airway cells. Am J Respir Cell Mol Biol 2010;42:424-431. 
-30 Schroeder TH, Lee MM, Yacono PW, et al: CFTR is a pattern recognition molecule that extracts Pseudomonas aeruginosa LPS from the outer membrane into epithelial cells and activates NF-kappa B translocation. Proc Natl Acad Sci USA 2002;99:6907-6912.

31 Jacquot J, Tabary O, Le Rouzic P, et al: Airway epithelial cell inflammatory signalling in cystic fibrosis. Int J Biochem Cell Biol 2008;40 1703-1715.

32 Imundo L, Barasch J, Prince A, et al: Cystic fibrosis epithelial cells have a receptor for pathogenic bacteria on their apical surface. Proc Natl Acad Sci USA 1995;92:3019-3023.

- 33 Campodonico VL, Gadjeva M, Paradis-Bleau C, et al: Airway epithelial control of Pseudomonas aeruginosa infection in cystic fibrosis. Trends Mol Med 2008;14:120-133.

-34 Gruenert DC, Willems M, Cassiman JJ, et al: Established cell lines used in cystic fibrosis research. J Cyst Fibros 2004;3:191-196.

- 35 Becker MN, Sauer MS, Muhlebach MS, et al: Cytokine secretion by cystic fibrosis airway epithelial cells. Am J Respir Crit Care Med 2004;169:645-653.

- 36 Carrabino S, Carpani D, Livraghi A, et al: Dysregulated interleukin-8 secretion and NFkappaB activity in human cystic fibrosis nasal epithelial cells. J Cyst Fibros 2006;5:113-119.

- 37 De Courcey F, Zholos AV, Atherton-Watson $\mathrm{H}$, et al: Development of primary human nasal epithelial cell cultures for the study of cystic fibrosis pathophysiology. Am J Physiol Cell Physiol 2012;303:1173-1179.

- 38 Stott JB, de Courcey F, Ennis M, et al: Functional and pharmacological characterization of volume-regulated anion channels in human normal and cystic fibrosis bronchial and nasal epithelial cells. Eur J Pharmacol 2014; 740:183-191.

39 Kelly C, Williams MT, Mitchell K, et al: Expression of the nuclear factor- $\mathrm{kB}$ inhibitor A20 is altered in the cystic fibrosis epithelium. Eur Respir J 2013;41:1315-1323.

40 Kelly C, Shields MD, Elborn JS, et al: A20 regulation of nuclear factor- $\kappa B$ : perspectives for inflammatory lung disease. Am J Respir Cell Mol Biol 2011;44:743-748.

41 Shembade N, Ma A, Harhaj EW: Inhibition of NF-kappaB signaling by A20 through disruption of ubiquitin enzyme complexes. Science 2010;327:1135-1139.

42 Vereecke L, Beyaert R, van Loo G: The ubiquitin-editing enzyme A20 (TNFAIP3) is a central regulator of immunopathology. Trends Immunol 2009;30:383-391.

43 Zaman MM, Gelrud A, Junaidi O, et al: Interleukin 8 secretion from monocytes of subjects heterozygous for the deltaF508 cystic fibrosis transmembrane conductance regulator gene mutation is altered. Clin Diagn Lab Immunol 2004;11:819-824.

-44 Colombo C, Costantini D, Rocchi A, et al: Cytokine levels in sputum of cystic fibrosis patients before and after antibiotic therapy. Pediatr Pulmonol 2005;40:15-21.
5 Karp CL, Flick LM, Park KW, et al: Defective lipoxin-mediated anti-inflammatory activity in the cystic fibrosis airway. Nat Immunol 2004;5:388-392.

46 Bonfield TL, Konstan MW, Berger M: Altered respiratory epithelial cell cytokine production in cystic fibrosis. J Allergy Clin Immunol 1999;104:72-78.

47 Yang Z, Klionsky DJ: An overview of the molecular mechanism of autophagy. Curr Top Microbiol Immunol 2009;335:1-32.

48 Trocoli A, Djavaheri-Mergny M: The complex interplay between autophagy and NF- $\mathrm{KB}$ signaling pathways in cancer cells. Am J Cancer Res 2011;1:629-649.

49 Schmid D, Münz C: Innate and adaptive immunity through autophagy. Immunity 2007 ; 27:11-21.

50 Luciani A, Villella VR, Esposito S, et al: Cystic fibrosis: a disorder with defective autophagy. Autophagy 2011;104-106.

51 Junkins RD, McCormick C, Lin T-J: The emerging potential of autophagy-based therapies in the treatment of cystic fibrosis lung infections. Autophagy 2014;538-547.

52 Abdulrahman BA, Khweek AA, Akhter A, et al: Autophagy stimulation by rapamycin suppresses lung inflammation and infection by Burkholderia cenocepacia in a model of cystic fibrosis. Autophagy 2011;7:1359-1370.

53 Opipari AW Jr, Boguski MS, Dixit VM: The A20 cDNA induced by tumour necrosis factor $\alpha$ encodes a novel type of zinc finger protein. J Biol Chem 1990;265:14705-14708.

54 Blackwell TS, Stecenko AA, Christman JW: Dysregulated NF-kappaB activation in cystic fibrosis: evidence for a primary inflammatory disorder. Am J Physiol Lung Cell Mol Physiol 2001;281:69-70.

55 Da Silva CG, Studer P, Skroch M, et al: A20 promotes liver regeneration by decreasing SOCS3 expression to enhance IL-6/STAT3 proliferative signals. Hepatology 2013;57: 2014-2025.

56 Mabilleau G, Chappard D, Sabokbar A: Role of the A20-TRAF6 axis in lipopolysaccharidemediated osteoclastogenesis. J Biol Chem 2011;286:3242-3249.

57 Shembade N, Parvatiyar K, Harhaj NS, et al: The ubiquitin-editing enzyme A20 requires RNF11 to downregulate NF-kappaB signalling. EMBO J 2009;28:513-522.

58 Shembade N, Pujari R, Harhaj NS, et al: The kinase IKKa inhibits activation of the transcription factor NF- $\kappa B$ by phosphorylating the regulatory molecule TAX1BP1. Nat Immunol 2011;12:834-843.

59 Wertz IE, O’Rourke KM, Zhou H, et al: Deubiquitination and ubiquitin ligase domains of A20 downregulate NF-kappaB signalling. Nature 2004;430:694-699.

60 De A, Dainichi T, Rathinam CV, et al: The deubiquitinase activity of A20 is dispensable for NF- $\kappa B$ signaling. EMBO Rep 2014;15: 775-783.
61 Opipari AW Jr, Hu HM, Yabkowitz R, et al: The A20 zinc finger protein protects cells from tumor necrosis factor cytotoxicity. J Biol Chem 1992;267:12424-12427.

62 Barmada MM, Brant SR, Nicolae DL, et al: A genome scan in 260 inflammatory bowel disease-affected relative pairs. Inflamm Bowel Dis 2004; 10:513-520.

63 Vereecke L, Sze M, Guire CM, et al: Enterocyte specific A20 deficiency sensitizes to tumour necrosis factor-induced toxicity and experimental colitis. J Exp Med 2010;207:15131523.

64 Onose A, Hashimoto S, Hayashi S, et al: An inhibitory effect of A20 on NF-kappaB activation in airway epithelium upon influenza virus infection. Eur J Pharmacol 2006;541:198204.

65 Tiesset H, Pierre M, Desseyn JL, et al: Dietary $(n-3)$ polyunsaturated fatty acids affect the kinetics of pro- and anti-inflammatory responses in mice with Pseudomonas aeruginosa lung infection. J Nutr 2009;139:82-89.

66 Gon Y, Asai Y, Hashimoto S, et al: A20 inhibits toll-like receptor 2- and 4-mediated interleukin-8 synthesis in airway epithelial cells. Am J Respir Cell Mol Biol 2004;31:330-336.

67 Sisto M, Lisi S, Lofrumento DD, et al: A failure of TNFAIP3 negative regulation maintains sustained NF-kappaB activation in Sjorgen's syndrome. Histochem Cell Biol 2011;135: 615-625.

68 Kelly C, Williams MT, Elborn JS, et al: Expression of the inflammatory regulator A20 correlates with lung function in patients with cystic fibrosis. J Cyst Fibros 2013;12:411-415.

69 Collett GP, Campbell FC: Overexpression of p65/RelA potentiates curcumin-induced apoptosis in HCT116 human colon cancer cells. Carcinogenesis 2006;27:1285-1291.

70 Hedden P: Plant biology: gibberellins close the lid. Nature 2008;456:455-456.

71 Holden NS, Rider CF, Bell MJ, et al: Enhancement of inflammatory mediator release by beta(2)-adrenoceptor agonists in airway epithelial cells is reversed by glucocorticoid action. Br J Pharmacol 2010;160:410-420.

72 Davis RH, Maro NP: Aloe vera and gibberellin. Anti-inflammatory activity in diabetes. J Am Podiatr Med Assoc 1989;79:24-26.

73 Jenkins PJ: Preparation and diabetic use of gibberellins. US patent No 0796859602 A1, 2006.

74 Oden P: The use of gibberellins for the treatment of prostatitis and psoriasis. European Patent No 0504254 A1, 1990.

75 Reihill J, Malcomson B, Barsden R, et al: Defective A20 signalling in cystic fibrosis: an anti-inflammatory action of gibberellin (abstract). J Cyst Fibros 2014;13:574.

76 Kang NI, Yoon HY, Lee YR, et al: A20 attenuates allergic airway inflammation in mice. J Immunol 2009;183:1488-1495.

77 Tan Y, Liu H, Yang H, et al: An inactivated Pseudomonas aeruginosa medicament inhibits airway allergic inflammation and improves epithelial functions. J Physiol Sci 2013;63:63-69. 
78 Mestre-Ferrandiz J, Sussex J, Towse A: The R\&D Cost of a New Medicine. London, Office of Health Economics UK, 2012.

79 Paul SM, Mytelka DS, Dunwiddie CT, et al: How to improve $\mathrm{R} \& \mathrm{D}$ productivity: the pharmaceutical industry's grand challenge. Nat Rev Drug Discov 2010;9:203-214.

80 Dickson M, Gagnon JP: Key factors in the rising cost of new drug discovery and development. Nat Rev Drug Discov 2004;3:417-429.

81 DiMasi JA, Hansen RW, Grabowski HG: The price of innovation: new estimates of drug development costs. J Health Econ 2003;22:151185.
82 Blume C, Davies DE: In vitro and ex vivo models of human asthma. Eur J Pharm Biopharm 2013;84:394-400.

83 Holmes AM, Solari R, Holgate ST: Animal models of asthma: value, limitations and opportunities for alternative approaches. Drug Discov Today 2011;16:659-670.

84 Ashburn TT, Thor KB: Drug repositioning: identifying and developing new uses for existing drugs. Nat Rev Drug Discov 2004;3:673683.

85 McArt DG, Zhang SD: Identification of candidate small-molecule therapeutics to cancer by gene-signature perturbation in connectivity mapping. PLoS One 2011;6:e16382.
86 Zhang SD, Gant TW: A simple and robust method for connecting small-molecule drugs using gene-expression signatures. BMC Bioinformatics 2008;9:258.

87 Ramsey JM, Kettyle LM, Sharpe DJ, et al: Entinostat prevents leukemia maintenance in a collaborating oncogene-dependent model of cytogenetically normal acute myeloid leukemia. Stem Cells 2013;31:1434-1445.

88 Barsden R, Elborn JS, Schock BC, et al: Connectivity mapping: an advanced approach to predict A20 inducing small molecules to reduce inflammation (abstract). J Cyst Fibros 2014; $13: 574$ 